\title{
Mechanical response of highly deformable thin shell composites
}

\author{
$\underline{\text { A. Schlothauer }}{ }^{1 *}$, Georgios A. Pappas ${ }^{1}$, P. Ermanni ${ }^{1}$ \\ ${ }^{1}$ Laboratory of Composite Materials and Adaptive Structures, ETH Zürich, \\ Leonhardstrasse 21, 8092 Zürich \\ *arthursc@ethz.ch
}

Carbon fiber (CF) reinforced thin shell (TS) composites with shell thickness below $300 \mu \mathrm{m}$ enable impressive flexibility in high modulus structures that can be utilized in deployable space structures [1] or mechanical meta-materials [2]. However, their mechanical response, especially in bending, is poorly understood and differs from composites higher thickness for conventional applications. TS composites show an increasing delay of compressive failure with decreasing thickness in large deformation bending tests [3], which allows them to withstand strains beyond $2 \%$ [4]. In these strain regimes, carbon fibers show highly non-linear constitutive behavior, which has drastic influence on stress distribution and failure. To date, no modelling approach exists, that can capture and predict TS composite's mechanical response, preventing a broader utilization of the impressive mechanical behavior. This paper presents a modelling approach that utilizes non-linear material modelling and micro/meso-mechanics in order to predict elastic response and failure in TS composites. The model extends a micro-mechanical model for compressive shear failure [5] to respect large strain gradients in thin shell's bending, while simultaneously considering non-linear material behavior. The results are corroborated by micro-mechanical numerical simulations as well as by large deformation bending tests (Figure 1a) to explain and verify the effects of thickness and micro-structure on the outstanding flexibility of thin shell composites (Figure 1b).
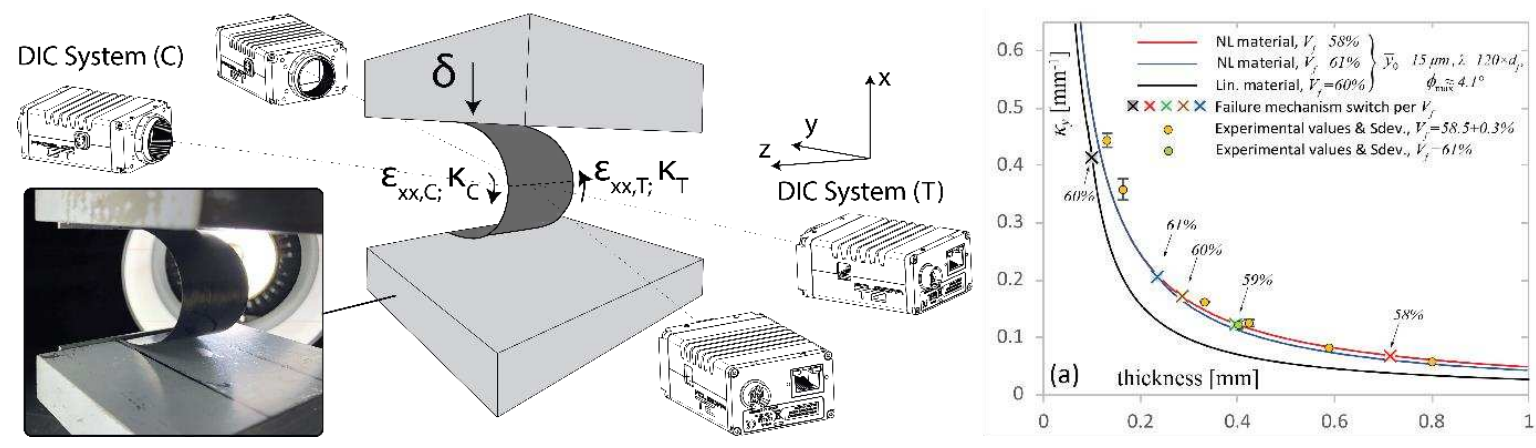

Figure 1. a) Large deformation bending of thin shell composites b) Prediction and experimental results of the failure curvature as a function of thickness. $V_{f}$ is the fiber volume fraction of the composite, $\mathrm{y}_{\mathrm{o}} \& \lambda$ refer to the intrinsic $\mathrm{CF}$ waviness with $\varphi_{\max }$ being the maximum fiber angle.

\section{References}

[1] T. W. Murphey, M. E. Peterson, and M. M. Grigoriev, "Large Strain Four-Point Bending of Thin Unidirectional Composites," J. Spacecr. Rockets, vol. 52, no. 3, pp. 882-895, 2015, doi: 10.2514/1.A32841.

[2] M. Sakovsky and P. Ermanni, "A thin-shell shape adaptable composite metamaterial," Compos. Struct., vol. 246, no. February, p. 112390, 2020, doi: 10.1016/j.compstruct.2020.112390.

[3] M. R. Wisnom and J. W. Atkinson, "Constrained buckling tests show increasing compressive strain to failure with increasing strain gradient," Compos. Part A Appl. Sci. Manuf., vol. 28, no. 11, pp. 959-964, 1997, doi: 10.1016/S1359-835X(97)00067-5.

[4] A. Schlothauer, G. A. Pappas, and P. Ermanni, "Material response and failure of highly deformable carbon fiber composite shells," Compos. Sci. Technol., vol. 199, no. May, 2020, doi: 10.1016/j.compscitech.2020.108378.

[5] B. Budiansky and N. A. Fleck, "Compressive failure of fibre composites," J. Mech. Phys. Solids, vol. 41, no. 1, pp. 183-211, 1993, doi: 10.1016/0022-5096(93)90068-Q. 